ScIDice

\section{Assessing Efficacy Of Temporomandibular Joint Arthrocentesis On Mouth Opening In Patients With Internal Derangement- A Retrospective Study}

Research Article

Swetha Bhat ${ }^{1}$, Senthilnathan Periasamy ${ }^{2 *}$, Murugaiyan Arun ${ }^{3}$

${ }^{1}$ Department of Oral and Maxillofacial Surgery, Saveetha Dental College and Hospitals, Saveetha Institute of Medical and Technical Sciences, Chennai, Tamil Nadu, India.

${ }^{2}$ Head of Department, Department of Oral and Maxillofacial Surgery, Saveetha Dental College and Hospitals, Saveetha Institute of Medical and Technical Sciences, Chennai, Tamil Nadu, India.

${ }^{3}$ Department of Oral and Maxillofacial Surgery, Saveetha Dental College and Hospitals, Saveetha Institute of Medical and Technical Sciences (SIMATS), Saveetha University, Chennai, India.

\title{
Abstract
}

\begin{abstract}
This study was designed to investigate the efficacy of temporomandibular joint arthrocentesis on mouth opening in the treatment of internal derangement patients. Arthrocentesis procedure was carried out as the treatment for 22 patients with internal derangement. Eight males and 14 females between 18 and 50 years of age comprised the study material with mainly the complaints of limited mouth opening and pain. Arthrocentesis was performed under aseptic conditions and effectiveness of the treatment was evaluated in terms of maximal mouth opening which were recorded at the follow up visit. There was an improvement in the postoperative maximal mouth opening in $13(59.09 \%)$ of cases with maximum improvement seen in the 21-30 years of age group, showing female predilection. Arthrocentesis is a simple, non-invasiveness and safe procedure for patients with internal derangement for improving mouth opening.
\end{abstract}

Keywords: Arthrocentesis; Internal Derangement; TMJ; Temporomandibular Joint Disorders; Maximal Mouth Opening.

\section{Introduction}

Temporomandibular joint (TMJ) is a joint between the glenoid fossa of the temporal bone and the condylar process of the mandible [12] and forms the very cornerstone of craniofacial integrity [35] Temporomandibular Disorders is a general term that indicates many clinical conditions involving temporomandibular joints [45] which encompasses a wide spectrum of conditions [26] accounts for the most of the orofacial pain rising from the musculoskeletal origin [40]. Arthrocentesis is an effective treatment for internal derangement of the TMJ [25]. Internal derangement is an orthopaedic term implying a mechanical drawback that interferes with the smooth action of a joint. It is therefore a functional diagnosis and for TMJ, the commonest internal derangement is displacement of the disc [13]. Most of the times, the disc displaces in an anterior, anterolateral and anteromedial direction. This multifactorial disease with multiple symptoms has a wide range of treatment modalities such as acupuncture medication, occlusal splinting and arthrocentesis to try to alleviate the pain and function complaints of patients suffering from TMJ dysfunctions [42]. The posterior band of the disc prolapses anteriorly relative to the superior surface of the condyle, instead of remaining back in its position between the condyle and glenoid fossa. As a consequence, the condyle gets positioned under the posterior disc attachment rather than under the disc, and the condyle closes on the posterior attachment instead of the disc itself.

Arthrocentesis was developed as a modification of TMJ Arthroscopy [37]. It was later found that the mechanical lysis and lavage of the joint was often successful in treating various internal derangements [19]. This procedure is extremely effective in eliminating joint adhesions, removal of inflammatory cytokines, correcting joint function at an early stage and reduction of pain [27]. However, the persistence of the effects on a long term basis is controversial [18]. But its usage as a palliative modality for acute

*Corresponding Author:

Senthilnathan Periasamy MDS,

Head of Department, Department of Oral and Maxillofacial Surgery, Saveetha Dental College and Hospitals, Saveetha Institute of Medical and Technical Sciences, Chennai, Tamil Nadu, India.

Tel: 9340040030

E-mail: senthilnathan@saveetha.com

Received: August 12, 2020

Accepted: September 29, 2020

Published: September 30, 2020

Citation: Swetha Bhat, Senthilnathan Periasamy, Murugaiyan Arun. Assessing Efficacy Of Temporomandibular Joint Arthrocentesis On Mouth Opening In Patients With Internal Derangement- A Retrospective Study. Int J Dentistry Oral Sci. 2020;S12:02:002:7-12. doi: http://dx.doi.org/10.19070/2377-8075-SI02-012002

Copyright: Senthilnathan Periasamy 2020 . This is an open-access article distributed under the terms of the Creative Commons Attribution License, which permits unrestricted use, distribution and reproduction in any medium, provided the original author and source are credited. 
episodes of degenerative changes are effective.

Previously our team had conducted numerous studies which include in vitro studies [20], reviews [33], survey [15, 16, 36, 38] and clinical trials $[1,2,6,14,34,39,46]$. Now we are focussing on retrospective studies, and the purpose of this study is to evaluate the efficacy of arthrocentesis as a method of treatment for internal derangement of the temporomandibular joint.

\section{Materials And Methods}

\section{Study setup}

This retrospective study was conducted among patients who reported to the Department of Oral and Maxillofacial Surgery, Saveetha Dental College, Chennai, India with restricted mouth opening and unilateral localised TMJ pain. A total of 86000 patient records were reviewed and analysed from June 2019 to March 2020. There were 22 patients clinically and radiographically (Panoramic and MRI) diagnosed with internal derangement out of which 8 were males and 14 were females.

\section{Inclusion and exclusion criteria}

The inclusion criteria of the study was:

- Clinical diagnosis of Anterior disc Displacement without reduction of TMJ

- Radiological diagnosis by MRI

- TMJ pain (Arthralgia)

- Restricted mouth opening with a prior history of click

- Only patients with complete records from the preoperative treatment and followup periods through the beginning of the study were included

The exclusion criteria comprise of:

- Presence of any other disorders involving the TMJ ( e.g. degenerative joint disease or collagen vascular disease)

- History of trauma

- Craniofacial/Dentofacial deformity

- Psychiatric illness

- Chronic headache

- Individuals who are not permanent residents of chennai

\section{Study parameters}

The following data were extracted for the purpose of the study

- Age of the patient

- Gender of the patient

- Preoperative Maximal mouth opening (MMO)

- Post operative MMO

\section{Data collection}

The data related to the stay parameters were obtained from among the patients who reported to the Department of Oral and Maxillofacial Surgery, Saveetha Dental College, Chennai from June 2019 to March 2020. Approval for the study was obtained from the Institutional Ethical Committee of Saveetha University (Ethical ap- proval number SDC/SIHEC/2020/DIASDATA/0619-0320). A written and verbal consent was obtained from patients for treatment and associated complications after the treatment outcome was fully explained to them.

\section{Procedure}

The procedure was carried out in complete aseptic conditions. The ear and preauricular skin over the joint was draped and painted using a topical antiseptic solution. A line was extending from the lateral canthus to the posterior or central point of tragus ( Hollmund- Hellsing line). Posterior point of entry- located along canthotragal line $10 \mathrm{~mm}$ from middle of tragus and $2 \mathrm{~mm}$ below the canthotragal line. The anterior point of entry was placed 10 $\mathrm{mm}$ further and $7 \mathrm{~mm}$ below the canthotragal line. This marking is the site of eminence of TMJ. The Auriculotemporal nerve was blocked with $2 \mathrm{ml}$ of Lignocaine and an 18 gauge needle is introduced into the superior joint space (posterior mark). $2 \mathrm{ml}$ of Ringer's lactate solution is injected into the distended compartment to establish a free flow of the solution through the superior joint space. A syringe filled with Hartmann's solution was then connected to one of the needles and the fluid $=\mathrm{d}$ was injected into the superior joint space. Second needle provides an outflow for the solution collected in a kidney tray. A total volume of 100 $\mathrm{ml}$ of solution was used to irrigate for the lavage of the superior joint space.

After lavage completion, needles are to be removed and the patients mandible gently manipulated in the vertical, lateral and protrusive excursions, to help further free the disc. The above procedure followed the technique described by Nitzan et al. (Nitzan, 2006). After treatment, patients were prescribed an analgesic and soft diet for the next week. Patient was asked to report after 1 week for recording the post-operative maximal mouth opening (MMO).

\section{Statistical analysis}

The IBM SPSS (version 23.0) software was used to tabulate and analyse the collected data. Non parametric data was analysed using descriptive statistics measuring frequency and percentage. Pearson's chi square test was used to assess the association between the improvement in MMO after arthrocentesis and age as well as gender.

\section{Results And Discussion}

Of the 22 cases, $14(63.6 \%)$ were females and 8 (36.4\%) were males (Figure 1). The mean age of patients was 30.36 years with maximum number of patients belonging to the 21-30 (50\%) year old age group (Figure 2). All the patients tolerated the procedure well and no complications were observed. This study showed an improvement in the maximal mouth opening in $13(59.09 \%)$ of cases and no improvement in $9(40.91 \%$ ) of cases (Figure 3 ). The preoperative mouth opening ranged from 13 to $39 \mathrm{~mm}$ with a mean of $30.95 \mathrm{~mm}$. The postoperative mouth opening ranged from 21 to $49 \mathrm{~mm}$ with a mean of $32.79 \mathrm{~mm}$ (Table 1). The maximum number of cases showing improvement belonged to 21 to $30(46 \%)$ years of age followed by 31 to $40(30.7 \%)$ of age. The age group of 11 to $20(7.69 \%)$ years of age showed the least number of cases presenting any improvement (Figure 4). Also there 
was a slight female predilection showing more number of successful cases among the female population (69\%) in comparison to the male population $(30.76 \%$ ) (Figure 5). However the $\mathrm{p}$ value for both the tests of association was $>0.05$, thus it was statistically insignificant.

Temporomandibular joint (TMJ) is one of the most important and versatile joints in the human body [8]. Temporomandibular disorders affect up to $25 \%$ of the population [7], its most important feature being pain, followed by restricted mandibular movement and noises from the TMJ. [44] and malocclusion might be one of the causes for it [5]. A paper published in the year 1991 by Nitzan and Dolwick, 1991 stated the technique of arthrocentesis and lavage has broadened the range for this procedure as a simple, non-invasive and an effective technique of persistent acute closed lock of the TMJ. It was first borne out of the use of TMJ arthroscopy not as a diagnostic tool but also as a therapeutic treatment modality showing remarkable improvement in pain, jaw opening and function in a selected number of patients.
When performed with pressure, the elimination of adhesions is the key element in the success of this method [47] Joint mobility increases as a result of the elimination of adhesions [17, 41, 48]. The elimination of inflammatory cytokines by arthrocentesis plays a role in pan reduction [17]. Alpaslan et al., [3] had evaluated MMO after arthrocentesis in patients with internal derangement of the TMJ. After an average follow up period of 22 months, they observed significantly reduced pain and dysfunction with significant increase in MMO. Monje Gil et al [22] reports that arthrocentesis was successful in $80 \%$ of studies examined. Some authors have reports that arthrocentesis is successful even in patients with advanced degenerative disease [30].

Sixty three percent of participants in our study were females. Joint disorders are observed more frequently in women than men and the data obtained in our study are favourable to those reported by Giraddi et al [10], Nitzan et al [28]. According to previous studies $[22,41]$, success of arthrocentesis has been determined according

Figure 1. The bar graph depicts the Baseline characteristics of Gender. $X$ axis represent gender, $Y$ axis represents frequency of patients. Female (63.64\%) patients included were more in this study in comparison to males (36.36\%). From the above graph, we can infer that there were greater number of females included in the study.

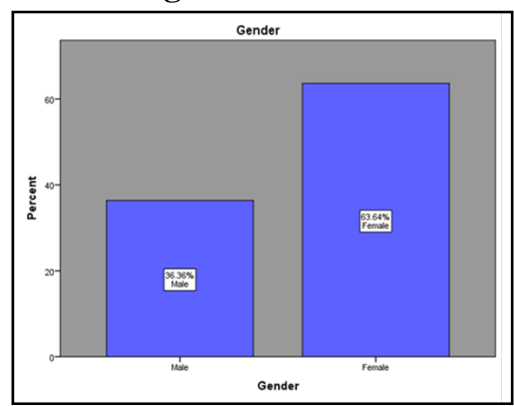

Figure 2. The pie chart represents Baseline characteristics of Age. 50\% of patients were in the age group of 21-30 years. From this pie chart we can infer that maximum number of patients belonged to 21-30 years age group.

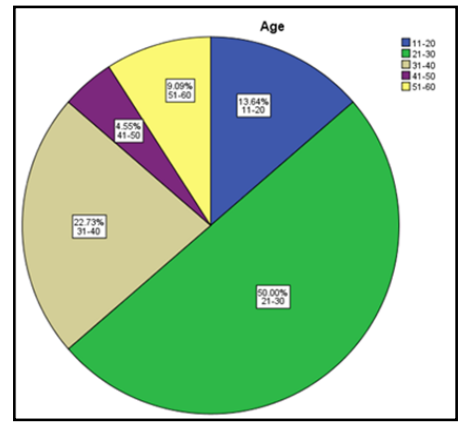

Figure 3. The pie chart represents the Frequency of patients showing improvement after Arthrocentesis procedure. 13 cases $(59.10 \%)$ showed improvement in mouth opening after arthrocentesis and 9 cases $(40.9 \%)$ showed no improvement.

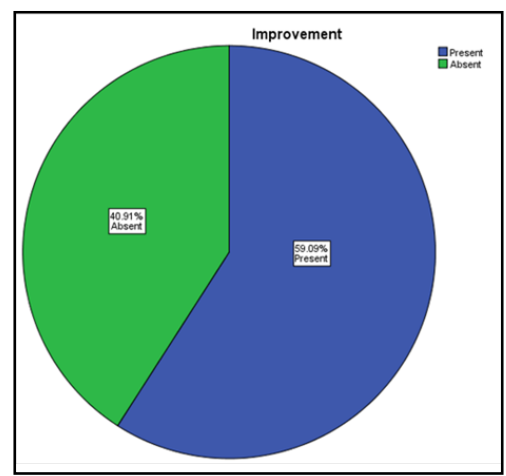


Table 1. ShowingPreoperative and postoperative maximal mouth opening (MMO) values.

\begin{tabular}{|c|c|}
\hline $\begin{array}{l}\text { Preoperative } \\
\text { MMO (in mm) }\end{array}$ & $\begin{array}{l}\text { Postoperative } \\
\text { MMO (in mm) }\end{array}$ \\
\hline 29 & 29 \\
\hline 27 & 27 \\
\hline 38 & 42 \\
\hline 32 & 29 \\
\hline 21.5 & 24 \\
\hline 35 & 32 \\
\hline 37 & 40 \\
\hline 24 & 21 \\
\hline 24 & 22 \\
\hline 34 & 30 \\
\hline 32 & 30 \\
\hline 20 & 25 \\
\hline 35 & 36 \\
\hline 33 & 34 \\
\hline 33 & 34 \\
\hline 29 & 32 \\
\hline 27 & 30 \\
\hline 39 & 40 \\
\hline 38 & 38 \\
\hline 32 & 33.5 \\
\hline 13 & 45 \\
\hline 48 & 49 \\
\hline
\end{tabular}

Figure 4. The below bar graph depicts the association between age and maximum mouth opening. $\mathrm{X}$ axis represents age, $\mathrm{Y}$ axis represents maximal mouth opening.Maximum number of successful cases was seen in patients age group in 21-30 years, followed by 31-40 years. Chi-sqaure test was done. $p>0.05$, statistically significant.Inference: maximum number of successful cases were seen in 21-30 years age group.

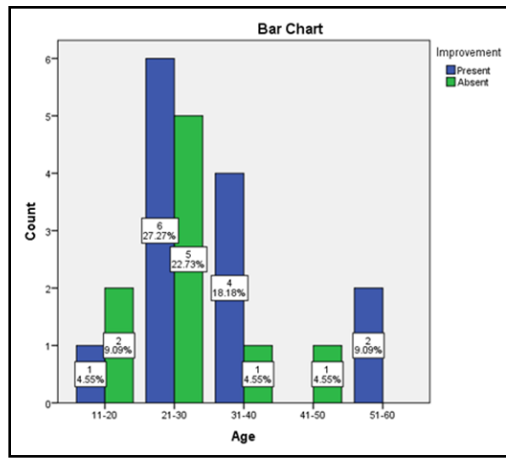

Figure 5. the below bar graph depicts the association between gender and maximum mouth opening.X axis depicts gender, $\mathrm{Y}$ axis depicts maximum mouth opening. Success rate was seen more in females $(69.03 \%)$ in comparison to males. Chi- square test was done. $\mathrm{p}>0.05$,statistically significant.Inference: success rate was more in females.

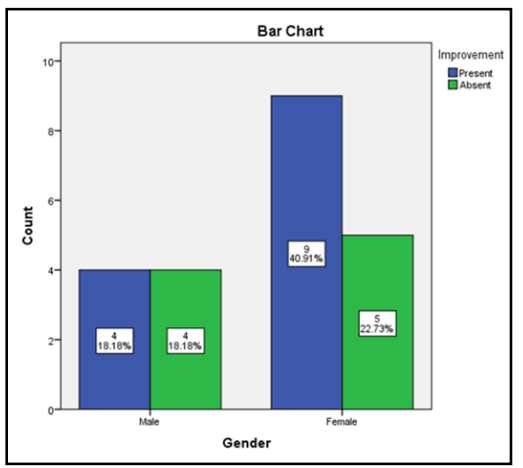


to increased MMO which is in agreement to our present study.

In addition to the effective treatment of acute closed lock, it has also been suggested that TMJ arthrocentesis and lavage may further be useful for management of osteoarthritis, early rheumatoid arthritis and acute intracapsular trauma with hemarthrosis of the TMJ [32]. In a study by Murakami et al [25], the mean patient age of successful cases was 27 years so age could be considered as an outcome of arthrocentesis. This compared favourably to our study, but the age difference was not significant enough to draw a conclusion. In this study, the success rate of the procedure as an initial treatment was $59.09 \%$. Murakami et al [25] stated a success rate of $70 \%$, Fridrich et al [9] showed $75 \%$ whereas Hosaka et al [13] showed $79 \%$. This difference could be accounted to the patient population and smaller sample size. Yilmaz et al [47] showed the success rate of the treatment to be $52.5 \%$ using AAOMS criteria. The above success rates compare favorably to our study results evaluating the improvement in MMO.

Complications of TMJ arthrocentesis and lavage include extravasation of fluid into surrounding tissue, Facial nerve injury (0.7$0.6 \%)[11,21,43]$, Fifth nerve deficit $(0.1-2.4 \%)$ [21], otic injury $(0.5-8.6 \%)[21,43]$, preauricular hematoma, superficial temporal artery aneurysm, arteriovenous fistula, transarticular perforation, intracranial perforations $v$, extradural hematoma, parapharyngeal swelling and intra articular problems [4].

The limitation of this study includes the evaluation of the treatment as successful or unsuccessful according to patient reactions and the difference in MMO, but requires a more detailed description of the patient's expectations. Parafunctional habits and history of trauma were not taken into consideration. Further studies regarding the efficacy of arthrocentesis could be done on a larger sample size. Also, Wilke's stages of internal derangement were not evaluated.

TMJ arthrocentesis and lavage in a simple non-invasive and less expensive technique with low morbidity. It can help in restoration of function and reduction of pain in a selected group of patients.

\section{Conclusion}

The most important aim of lysis and lavage of the joint are to eliminate inflamed synovial fluid to release the disc, reduce the pain and enable movement of the joint. Within limits, the study shows significant success rate of temporomandibular joint arthrocentesis in the age group 21-30 years with female predilection by evaluation of mouth opening in patients with internal derangement.

\section{References}

[1]. Abhinav RP, Selvarasu K, Maheswari GU, Taltia AA. The Patterns and Etiology of Maxillofacial Trauma in South India. Ann Maxillofac Surg. 2019 Jan-Jun;9(1):114-117. Pubmed PMID: 31293938.

[2]. Sweta VR, Abhinav RP, Ramesh A. Role of Virtual Reality in Pain Perception of Patients Following the Administration of Local Anesthesia. Ann Maxillofac Surg. 2019 Jan-Jun;9(1):110-113. Pubmed PMID: 31293937.

[3]. Alpaslan C, Dolwick MF, Heft MW. Five-year retrospective evaluation of temporomandibular joint arthrocentesis. Int J Oral Maxillofac Surg. 2003 Jun;32(3):263-7. Pubmed PMID: 12767872.

[4]. Carls FR, Engelke W, Locher MC, Sailer HF. Complications following arthroscopy of the temporomandibular joint: analysis covering a 10-year pe- riod (451 arthroscopies). J Craniomaxillofac Surg. 1996 Feb;24(1):12-5. Pubmed PMID: 8707936.

[5]. Chokalingam S, AS F. Malocclusion and TMJ disease-A review of literature. IOSR JDMS. 2014;13(1):71-3.

[6]. Christabel A, Anantanarayanan P, Subash P, Soh CL, Ramanathan M, Muthusekhar MR, et al. Comparison of pterygomaxillary dysjunction with tuberosity separation in isolated Le Fort I osteotomies: a prospective, multi-centre, triple-blind, randomized controlled trial. Int J Oral Maxillofac Surg. 2016 Feb;45(2):180-5. Pubmed PMID: 26338075.

[7]. Elumalai, M. et al. (no date) 'Association of signs and symptoms of temporomandibular joint disorder between gender, partial edentulism, and morphological occlusion among dental patients in Chennai'. Available at: http:// jprsolutions.info/files/final-file-5c1b4b73f07869.14159870.pdf.

[8]. Ezhil I, Arun AV, Kumar MP. Morphological changes of the mandibular condyle following orthodontic treatment. Drug Invention Today. 2018 Sep $2 ; 10$.

[9]. Fridrich KL, Wise JM, Zeitler DL. Prospective comparison of arthroscopy and arthrocentesis for temporomandibular joint disorders. J Oral Maxillofac Surg. 1996 Jul;54(7):816-20; discussion 821. Pubmed PMID: 8676225.

[10]. Giraddi GB, Siddaraju A, Kumar B, Singh C. Internal derangement of temporomandibular joint: an evaluation of effect of corticosteroid injection compared with injection of sodium hyaluronate after arthrocentesis. J Maxillofac Oral Surg. 2012 Sep;11(3):258-63. Pubmed PMID: 23997474.

[11]. González-García R, Rodríguez-Campo FJ, Escorial-Hernández V, MuńozGuerra MF, Sastre-Pérez J, Naval-Gías L, et al. Complications of temporomandibular joint arthroscopy: a retrospective analytic study of 670 arthroscopic procedures. J Oral Maxillofac Surg. 2006 Nov;64(11):1587-91. Pubmed PMID: 17052583.

[12]. Govindaraj A, Dinesh SP, Srirengalakshmi M. Relationship between temporomandibular joint problem and malocclusion-An awareness survey among dental students and dentists. Drug Invention Today. 2019 Feb 1;11(2).

[13]. Hosaka H, Murakami K, Goto K, lizuka T. Outcome of arthrocentesis for temporomandibular joint with closed lock at 3 years follow-up. Oral Surg Oral Med Oral Pathol Oral Radiol Endod. 1996 Nov;82(5):501-4. Pubmed PMID: 8936512.

[14]. Jesudasan JS, Wahab PU, Sekhar MR. Effectiveness of $0.2 \%$ chlorhexidine gel and a eugenol-based paste on postoperative alveolar osteitis in patients having third molars extracted: a randomised controlled clinical trial. Br J Oral Maxillofac Surg. 2015 Nov;53(9):826-30. Pubmed PMID: 26188932.

[15]. Kumar S, Rahman RE. Knowledge, awareness, and practices regarding biomedical waste management among undergraduate dental students. Asian Journal of Pharmaceutical and Clinical Research. 2017;10(8):341.

[16]. Kumar S, Sneha, S. 'Knowledge and awareness regarding antibiotic prophylaxis for infective endocarditis among undergraduate dental students'. Asian Journal of Pharmaceutical and Clinical Research.2016;154. doi: 10.22159/ ajpcr.2016.v9s2.13405.

[17]. Lee HS, Baek HS, Song DS, Kim HC, Kim HG, Kim BJ, et al. Effect of simultaneous therapy of arthrocentesis and occlusal splints on temporomandibular disorders: anterior disc displacement without reduction. J Korean Assoc Oral Maxillofac Surg. 2013 Feb;39(1):14-20. Pubmed PMID: 24471012.

[18]. List T, Jensen RH. Temporomandibular disorders: Old ideas and new concepts. Cephalalgia. 2017 Jun;37(7):692-704. Pubmed PMID: 28068790.

[19]. Malik AH, Shah AA. Efficacy of Temporomandibular Joint Arthrocentesis on Mouth Opening and Pain in the Treatment of Internal Derangement of TMJ-A Clinical Study. J Maxillofac Oral Surg. 2014 Sep;13(3):244-8. Pubmed PMID: 25018595.

[20]. Marimuthu M, Andiappan M, Wahab A, Muthusekhar MR, Balakrishnan A, Shanmugam S. Canonical Wnt pathway gene expression and their clinical correlation in oral squamous cell carcinoma. Indian J Dent Res. 2018 MayJun;29(3):291-297. Pubmed PMID: 29900911.

[21]. McCain JP, Sanders B, Koslin MG, Quinn JH, Peters PB, Indresano AT Temporomandibular joint arthroscopy: a 6-year multicenter retrospective study of 4,831 joints. J Oral Maxillofac Surg. 1992 Sep;50(9):926-30. Pubmed PMID: 1506966.

[22]. Monje-Gil F, Nitzan D, González-Garcia R. Temporomandibular joint arthrocentesis. Review of the literature. Med Oral Patol Oral Cir Bucal. 2012 Jul 1;17(4):e575-81. Pubmed PMID: 22322493.

[23]. Kumar S. Relationship between dental anxiety and pain experience during dental extractions. Asian Journal of Pharmaceutical and Clinical Research. 2017;10(3):458-.

[24]. Kumar $S$. The emerging role of botulinum toxin in the treatment of orofacial disorders: Literature update. Asian Journal of Pharmaceutical and Clinical Research. 2017;10(9):21-9.

[25]. Murakami K, Hosaka H, Moriya Y, Segami N, lizuka T. Short-term treatment outcome study for the management of temporomandibular joint closed lock. A comparison of arthrocentesis to nonsurgical therapy and ar- 
throscopic lysis and lavage. Oral Surg Oral Med Oral Pathol Oral Radiol Endod. 1995 Sep;80(3):253-7. Pubmed PMID: 7489265.

[26]. Muthukrishnan A, Sekar GS. Prevalence of temporomandibular disorders in Chennai population. Journal of Indian Academy of Oral Medicine and Radiology. 2015 Oct 1;27(4):508.

[27]. Nan Z, Guoliang J, Zhongyin W. [Clinical symptoms and temporomandibular joint disc deformity study of Wilkes III stage patients treated with arthrocentesis]. Hua Xi Kou Qiang Yi Xue Za Zhi. 2015 Dec;33(6):585-8. Chinese. Pubmed PMID: 27051949.

[28]. Nitzan DW. Rationale and indications for arthrocentesis of the temporomandibular joint. Alpha Omegan. 2003 Jul;96(2):57-63. Pubmed PMID: 12955783.

[29]. Nitzan DW. Arthrocentesis--incentives for using this minimally invasive approach for temporomandibular disorders. Oral Maxillofac Surg Clin North Am. 2006 Aug;18(3):311-28, vi. Pubmed PMID: 18088835.

[30]. Nitzan DW, Svidovsky J, Zini A, Zadik Y. Effect of Arthrocentesis on Symptomatic Osteoarthritis of the Temporomandibular Joint and Analysis of the Effect of Preoperative Clinical and Radiologic Features. J Oral Maxillofac Surg. 2017 Feb;75(2):260-267. Pubmed PMID: 27643632.

[31]. Nitzan DW, Dolwick MF. An alternative explanation for the genesis of closed-lock symptoms in the internal derangement process. J Oral Maxillofac Surg. 1991 Aug;49(8):810-5; discussion 815-6. Pubmed PMID: 2072192.

[32]. Nitzan DW, Dolwick MF, Martinez GA. Temporomandibular joint arthrocentesis: a simplified treatment for severe, limited mouth opening. J Oral Maxillofac Surg. 1991 Nov;49(11):1163-7; discussion 1168-70. Pubmed PMID: 1941330.

[33]. Packiri S, Gurunathan D, Selvarasu K. Management of Paediatric Oral Ranula: A Systematic Review. J Clin Diagn Res. 2017 Sep;11(9):ZE06-ZE09. Pubmed PMID: 29207849.

[34]. Patil SB, Durairaj D, Suresh Kumar G, Karthikeyan D, Pradeep D. Comparison of Extended Nasolabial Flap Versus Buccal Fat Pad Graft in the Surgical Management of Oral Submucous Fibrosis: A Prospective Pilot Study. J Maxillofac Oral Surg. 2017 Sep;16(3):312-321. Pubmed PMID: 28717289.

[35]. Patturaja K, Krishnamoorthy K. Treatment and management of temporomandibular joint ankylosis-A Review. Research Journal of Pharmacy and Technology. 2016 Oct 28;9(10):1668-70.

[36]. Patturaja K, Pradeep D. Awareness of Basic Dental Procedure among General Population. Research Journal of Pharmacy and Technology. 2016 Sep $1 ; 9(9): 1349$

[37]. Quintessenz Verlags-GmbH, Berlin and Onlineredaktion.Laskin/Greene/ Hylander: Temporomandibular Disorders - Books - Quintessence Publishing Deutschland, Quintessenz Verlags-GmbH, Berlin, Onlineredaktion. 2020. Available at: https://www.quintessenz.de/books.php?idp=13561\&qtw_ language $=$ en (Accessed: 1 June 2020).

[38]. Rahman RE, Mp SK. Knowledge, attitude, and awareness of dental undergraduate students regarding human immunodeficiency virus/acquired immunodeficiency syndrome patients. Asian J Pharm Clin Res [Internet]. 2017;10(5):175-80.

[39]. Rao TD, Kumar MS. Analgesic efficacy of paracetamol vs ketorolac after dental extractions. Research Journal of Pharmacy and Technology. 2018 Aug 1;11(8):3375-9

[40]. Sam P, Dhanraj M, Jain AR. Treatment of temporomandibular disordersKnowledge, attitude, and practice among general practicing dentists-A survey. Drug Invention Today. 2018 May 1;10(5).

[41]. Sharma A, Rana AS, Jain G, Kalra P, Gupta D, Sharma S. Evaluation of efficacy of arthrocentesis (with normal saline) with or without sodium hyaluronate in treatment of internal derangement of TMJ - A prospective randomized study in 20 patients. J Oral Biol Craniofac Res. 2013 SepDec;3(3):112-9. Pubmed PMID: 25737898.

[42]. Srinivas MR, James D, Muthusekhar MR. Efficacy of Hyaluronic Acid in the Treatment of Internal Derangement-Clinical Study. Research Journal of Pharmacy and Technology. 2018;11(8):3483-5.

[43]. Tsuyama M, Kondoh T, Seto K, Fukuda J. Complications of temporomandibular joint arthroscopy: a retrospective analysis of 301 lysis and lavage procedures performed using the triangulation technique. J Oral Maxillofac Surg. 2000 May;58(5):500-5; discussion 505-6. Pubmed PMID: 10800905.

[44]. Veerappan RR, Gopal M. Comparison of the diagnostic accuracy of CBCT and conventional CT in detecting degenerative osseous changes of the TMJ: A systematic review. Journal of Indian Academy of Oral Medicine and Radiology. 2015 Jan 1;27(1):81.

[45]. Lakshmi LG, Narayan V. Prevalence of disk displacement disorders of tmj among dental students. International Journal of Research in Social Sciences. 2017;7(7):630-6.

[46]. Vijayakumar Jain S, Muthusekhar MR, Baig MF, Senthilnathan P, Loganathan S, Abdul Wahab PU, et al. Evaluation of Three-Dimensional Changes in Pharyngeal Airway Following Isolated Lefort One Osteotomy for the Correction of Vertical Maxillary Excess: A Prospective Study. J Maxillofac Oral Surg. 2019 Mar;18(1):139-146. Pubmed PMID: 30728705.

[47]. Yilmaz O, Candirli C, Balaban E, Demirkol M. Evaluation of success criteria for temporomandibular joint arthrocentesis. Journal of the Korean Association of Oral and Maxillofacial Surgeons. 2019 Feb;45(1):15.

[48]. Yura S, Totsuka Y, Yoshikawa T, Inoue N. Can arthrocentesis release intracapsular adhesions? Arthroscopic findings before and after irrigation under sufficient hydraulic pressure. J Oral Maxillofac Surg. 2003 Nov;61(11):1253-6. Pubmed PMID: 14613079. 